\title{
Beauveria bassiana em associação com milho geneticamente modificado no manejo de Spodoptera frugiperda e Rhopalosiphum maidis
}

\author{
Beauveria bassiana in association with genetically modified maize on \\ Spodoptera frugiperda and Rhopalosiphum maidis management
}

\begin{abstract}
Renato Franco Oliveira de Moraes ${ }^{1 *}$, Luciana Cláudia Toscano ${ }^{2}$, Marcelo Francisco Arantes Pereira ${ }^{3}$, Valter Luis Pietrobom ${ }^{3}$, Cecília Aparecida Moreira dos Santos Barboza ${ }^{3}$, Wilson Itamar Maruyama ${ }^{2}$
\end{abstract}

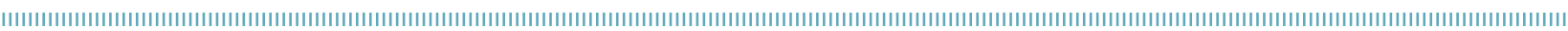

RESUMO: O objetivo deste trabalho foi avaliar a eficiência do fungo Beauveria bassiana (isolado CG 716) no manejo de Spodoptera frugiperda e Rhopalosiphum maidis em milho. Diante disso, montou-se um experimento em blocos ao acaso, utilizando parcelas subdivididas, contendo dez tratamentos e quatro repetiçóes. Os tratamentos foram: $B$. bassiana, formulado em óleo vegetal, nas doses de 2,0, 4,0 e 6,0 x $10^{12}$ conídios ha $^{-1}$, lambda-cialotrina $\left(7,5\right.$ i.a. ha $\left.{ }^{-1}\right)$ e testemunha (sem aplicação). As aplicaçóes foram realizadas a partir dos 10 dias após a emergência (DAE) das plantas, sendo repetidas aos 16, 23 e 31 DAE. As avaliaçóes foram realizadas semanalmente coletando-se dez plantas consecutivas por parcela e armazenadas em sacos plásticos, para posterior destruição do cartucho e contagem de lagartas, pulgóes e inimigos naturais em laboratório. Não ocorreram diferenças significativas em populaçóes de $S$. frugiperda e $R$. maidis em lavouras de milho submetidas ou não a aplicações de defensivos; entretanto, na variedade convencional, aos $40 \mathrm{DAE}$, foi constatado que um maior número médio pulgôes sob aplicação do bioinseticida na dosagem de 2,0 x $10^{12}$ conídios ha ${ }^{-1}$. B. bassiana, em associação com a tecnologia $B t$, não produziu resultados satisfatórios no controle de $S$. frugiperda e $R$. maidis nas condições em que foi testado.

PALAVRAS-CHAVE: lagarta-do-cartucho; fungo entomopatogênicos; pulgão-do-milho; Zea mays; transgênicos.
ABSTRACT: The objective of this study work was to evaluate the efficiency of the fungus Beauveria bassiana (isolate CG 716) to control Spoodptera frugiperda and Rhopalosiphum maidis on maize. Front this, was set up in randomized blocks split plots design, with 10 treatments and four replications. Treatments were applied to plots: $B$. bassiana formulated in vegetable oil at doses of 2.0, 4.0 and $6.0 \times 10^{12}$ conidia ha ${ }^{-1}$, lambda-cyhalothrin (7.5 a.i. ha ${ }^{-1}$ ) and control (no application). Applications were made weekly. Assessments were performed before each application of the products, collecting 10 consecutive plants per plot for subsequent and storing in plastic bag from destruction of the whorl of maize and counting the number of fall armyworm larvae, aphids and natural enemies in laboratory. There were no significant differences among treatments in relation to the population of $S$. frugiperda larvae and $R$. maidis in corn fields treated or not treated with of defensives applications, however, higher number of $R$. maidis was observed on the conventional cultivar at 40 days after emergence (DAE) treated with the bioinsecticide $B$. bassiana at a dose of $2.0 \times 10^{12}$ conidia ha ${ }^{-1}$. B. bassiana associated with $B t$ technology does not show satisfactory results to control $S$. frugiperda.

KEYWORDS: armyworms; entomopathogenic fungis; aphid corn; Zea mays; transgenics.

'Departamento de Fitossanidade, Faculdade de Ciências Agrárias e Veterinárias, Universidade Estadual Paulista “Júlio de Mesquita Filho" (UNESP) - Jaboticabal (SP), Brasil. universidade Estadual de Mato Grosso do Sul (UEMS) - Cassilândia (MS), Brasil.

${ }^{3}$ Unidade de Pesquisa e Desenvolvimento (UPD)/Agência Paulista de Tecnologia dos Agronegócios (APTA) - São José do Rio Preto (SP), Brasil.

*Autor correspondente: renatomoraes2@hotmail.com

Recebido em: 04/11/2013. Aceito em: 21/10/2015 


\section{INTRODUÇÃO}

A lagarta-do-cartucho, Spodoptera frugiperda (J. E. SмIтH, 1797) (Lepdoptera: Noctuidae), é considerada a principal praga da cultura do milho no Brasil (VAlicente; Tuelher, 2009), tendo seu ataque ocorrido em todos os estádios de desenvolvimento da cultura, podendo gerar perdas de até $38 \%$ na produção (Viana et al., 2006). Outra praga que vem ganhando destaque nos danos ocasionados à cultura é o pulgão Rhopalosiphum maidis (FIтcH, 1856) (Hemiptera: Aphididae) (Fonseca et al., 2004) que, além da sucçâa de seiva, pode transmitir viroses, como o mosaico, e proporcionar, por meio de suas excreçôes, o desenvolvimento de fumagina.

$\mathrm{O}$ manejo de pragas na cultura do milho tem sido à base do uso de inseticidas químicos, em especial o controle da espécie $S$. frugiperda. Essas medidas visam minimizar a ação dessa praga, evitando, assim, perdas na produtividade (CRUZ et al., 1999).

Entretanto, quando o controle químico e empregado de forma contínua e seu uso se dá de forma incorreta, há grande risco de contaminação aos trabalhadores e ao meio ambiente, causando efeito sobre populaçóes de inimigos naturais e, principalmente, seleção de populaçóes resistentes (Dourado, 2009), ficando evidente a necessidade de se buscar de novas táticas de controle mais seguras e de menor risco ao meio ambiente.

Segundo Alves (1998), o uso dos entomopatógenos visando ao controle de insetos tem aumentado significativamente, principalmente por ser uma alternativa eficaz e não contaminante, fato esse observado por MarTins et al. (2009) e GUTIERrez et al. (1995) na realização de experimentos utilizando entomopatógenos. Dentre os agentes de controle microbiano, os fungos das espécies Beauveria bassiana (Vuillemin, 1912) e Metarhizium anisopliae (Metsch) Sorokin, 1883, têm destaque no controle de pragas em várias culturas (THOMAzonI et al., 2009).

Outros agentes de grande importância no controle biológico de insetos-praga são os conhecidos inimigos naturais, sendo Doru luteipes (Scudder, 1876) (Dermaptera: Forficulidae) o mais importante na cultura do milho, por predar diretamente ovos e lagartas de primeiros ínstares de $S$. frugiperda (REDOAN, 2011).

Além desses métodos de controle que corroboram os preceitos do Manejo Integrado de Pragas, a adoção de variedades resistentes vem sendo amplamente utilizada para minimizar a ação de pragas, e a adoção dos transgênicos é uma alternativa que favorece o manejo de insetos-pragas (BorÉm; SANTOS, 2002).

Diante disso, o objetivo desta pesquisa foi avaliar a eficiência de diferentes doses do fungo $B$. bassiana (isolado CG 716) no controle de $S$. frugiperda e $R$. maidis em cultivares de milho transgênico e convencional.

\section{MATERIAL E MÉTODO}

A cultura do milho foi implantada na Unidade de Pesquisa e Desenvolvimento (UPD) de Sáo José do Rio Preto, Agência Paulista de Tecnologia dos Agronegócios (APTA), Regional do Centro Norte, localizada no município de São José do Rio Preto (SP) (4923' O, 2048' S, altitude $468 \mathrm{~m}$ ), na safra 2010/2011, no período de novembro de 2010 a janeiro de 2011, utilizando-se dois cultivares: DKB 175 (convencional) e DKB 390 VT PRO (transgênico). Os cultivares foram semeados utilizando recomendaçôes técnicas para a cultura do milho, sob espaçamento de $0,80 \mathrm{~cm}$ entre linhas e densidade de 5 a 6 plantas por $\mathrm{m}$.

Utilizou-se o delineamento experimental de blocos ao acaso, com parcelas subdivididas, sendo produtos (Fator 1) e cultivares (Fator 2), com dez tratamentos e quatro repetiçóes. Os tratamentos aplicados às parcelas de ambos os cultivares foram: $B$. bassiana, formulado em óleo vegetal, nas doses de 2,0, 4,0 e 6,0 × $10^{12}$ conídios ha ${ }^{-1}$, lambda-cialotrina (7,5 i.a. ha $\left.{ }^{-1}\right)$ e testemunha (sem aplicação). Foi adotado o tratamento com lambda-cialotrina $\left(7,5\right.$ i.a. ha $\left.{ }^{-1}\right)$ como padrão, por este ser um inseticida registrado no Ministério da Agricultura para a cultura do milho (Agrofit, 2013). Cada parcela foi constituída por 12 linhas de plantio e $10 \mathrm{~m}$ de comprimento, totalizando $96 \mathrm{~m}^{2}$.

Ponderando o ataque da lagarta do cartucho e a ação cumulativa do agente microbiano, as aplicaçôes dos tratamentos, incluído o químico padrão, foram efetuadas, semanalmente, aos 10, 16, 23 e 31 dias após a emergência (DAE) das plantas, sob as seguintes condiçōes climáticas: temperatura média de $26,3,29,8,28,1$ e $29^{\circ} \mathrm{C}$ e umidade relativa de $70,5,53,7$, 46,5 e $74,7 \%$, respectivamente, ressaltando que essas aplicaçôes foram realizadas sempre ao fim do dia. As aplicaçôes dos produtos foram efetuadas com pulverizador pressurizado a $\mathrm{CO}_{2}$, acoplado com pontas de pulverizaçáo do tipo leque (XR Teejet 8004 vs), sob pressão de trabalho de 2,5 bar, utilizando volume de calda de $500 \mathrm{~L} \mathrm{ha}^{-1}$.

As avaliaçôes ocorreram previamente e semanalmente a cada aplicaçáo dos produtos, coletando-se dez plantas consecutivas por parcela, para posterior destruição do cartucho e contagem de lagartas, pulgóes e inimigos naturais em laboratório.

Aos 28 DAE foi realizada uma avaliação visual para quantificação do dano causado pela lagarta-do-cartucho, observando 2 pontos com 10 plantas por unidade experimental, atribuindo notas de acordo com a escala proposta por CARVALHO (1970), em que: $0=$ plantas sem folhas danificadas; $1=$ plantas com raspadura nas folhas; 2 = plantas apresentando furo nas folhas; 3 = plantas apresentando dano nas folhas e alguma lesão no cartucho; 4 = plantas apresentando cartucho destruído; 5 = plantas mortas, para verificação do dano causado pela lagarta-do-cartucho.

Os dados foram submetidos à análise de variância Anova pelo teste $\mathrm{F}$, as médias dos tratamentos foram comparadas pelo teste de Tukey $(\mathrm{p}<0,05)$ e a porcentagem de eficiência dos inseticidas no 
controle de $S$. frugiperda e $R$. maidis foi calculada de acordo com a equação de Аввотт (1925): \% $\mathrm{EF}=(\mathrm{T}-\mathrm{t}) * 100 / \mathrm{T}$, onde $\mathrm{T}=$ testemunha (sem aplicação), $\mathrm{t}=$ tratamento (controle testado).

\section{RESULTADOS E DISCUSSÃO}

As populaçôes de $S$. frugiperda não diferiram significativamente em culturas de milho transgênico (DKB 390 VT PRO) submetidas ou não a aplicaçốes de defensivos, durante a fase vegetativa (Tabela 1). Porém, no cultivar convencional (DKB 175), aos 15 DAE, verifica-se, em lavouras de milho sob aplicação de 2,0 x $10^{12}$ conídios ha ${ }^{-1}$, menor número médio de lagartas.

Aos $22 \mathrm{DAE}$, melhores resultados foram observados em plantas de milho submetidas às doses de 4,0 e 6,0 x $10^{12}$ conídios ha ${ }^{-1}$ (Tabela 1), corroborando Auves (1998), que reporta que a ação dos fungos entomopatogênicos em insetos acontece de forma lenta. Esses resultados ainda são semelhantes aos encontrados por MarTins et al. (2009), que afirmaram a não ocorrência de diferenças estatísticas entre plantas de milho submetidas a doses de 0,5 e $1,0 \times 10^{9}$ conídios ha ${ }^{-1}$ do bioinseticida $B$. bassiana e dos inseticidas químicos teflubenzuron e spinosad aos 15 e 21 dias após a aplicação (DAA).

Verifica-se que $B$. bassiana nas doses testadas não apresentou, de modo geral, uma boa eficiência no controle da praga no cultivar DKB 175 (convencional) em condição de campo, visto que os melhores resultados foram $25 \%$ na dose de $2,0 \mathrm{x}$ $10^{12}$ conídios ha $^{-1}$ e $25 \%$ na dose de $6,0 \times 10^{12}$ conídios ha ${ }^{-1}$ para 15 e 40 DAE, respectivamente (Tabela 1).

A igualdade entre os produtos utilizados permite verificar que por mais que as doses sejam diferentes, tais quantidades não influenciam na mortalidade das lagartas. Esse resultado pode ter se relacionado com as condiçóes climáticas, a forma de utilizaçáo e/ou até mesmo a dosagem desses entomopatógenos.

Estes resultados diferem dos encontrados por MarTins et al. (2009), que verificaram eficiência de 28 e $30 \%$ sob dose de 0,5 e $1,0 \times 10^{9}$ conídios ha $^{-1}$, respectivamente, aos 21 DAA.

Em um trabalho sob condiçóes de campo, Canini et al. (2008), Afonso Junior (2009) e Canini et al. (2009) não observaram sucesso quanto à eficiência dos fungos $M$. anisopliae e $B$. bassiana em milho safrinha.

Com uma dose menor, e em condiçóes de laboratório (onde os resultados são os mais extremos possíveis), GUTIERREZ et al. (1995) verificaram que o fungo $M$. anisopliae causou $100 \%$ de mortalidade, após um período de 8 a 10 dias da aplicação de lagartas de $S$. frugiperda na concentração de $4,11 \times 10^{2}$ conídios $/ \mathrm{mL}$, evidenciando, assim, o potencial desses agentes no controle de pragas.

Fica evidente a necessidade de se realizar novas pesquisas em campo para desenvolver uma metodologia, para que, então, o emprego desses entomopatógenos se estabeleça e apresente resultados positivos.

Tabela 1. Número (média + erro padrão) de lagartas de diferentes tamanhos de Spodoptera frugiperda em dez plantas de milho transgênico e convencional submetidas a aplicações do fungo Beauveria bassiana em condições de campo. Agência Paulista de Tecnologia dos Agronegócios-Regional, São José do Rio Preto (SP), 2010-2011.

\begin{tabular}{|c|c|c|c|c|c|c|}
\hline \multirow{2}{*}{$\begin{array}{l}\text { Produtos } \\
\text { Dose i.a. ha-1 ou conídios ha-1 }\end{array}$} & \multicolumn{2}{|c|}{$9 \mathrm{DAE}$} & \multicolumn{2}{|c|}{$15 \mathrm{DAE}$} & \multicolumn{2}{|c|}{22 DAE } \\
\hline & DKB 175 & $\begin{array}{l}\text { DKB } 390 \text { VT } \\
\text { PRO } \pm \text { EP }\end{array}$ & DKB $175 \pm E P$ & $\begin{array}{c}\text { DKB } 390 \text { VT PRO } \\
\pm \text { EP }\end{array}$ & DKB $175 \pm E P$ & $\begin{array}{l}\text { DKB } 390 \text { VT } \\
\text { PRO } \pm \text { EP }\end{array}$ \\
\hline B. bassiana $2,0 \times 10^{12}$ & $9,0 \pm 0,8 \mathrm{aA}$ & $2,7 \pm 0,5$ aA & $16,5 \pm 1,1 \mathrm{abA}$ & $0,5 \pm 0,2 \mathrm{aB}$ & $35,5 \pm 3,1 \mathrm{bA}$ & $4,5 \pm 1,5 \mathrm{aB}$ \\
\hline B. bassiana $4,0 \times 10^{12}$ & $12,5 \pm 2,4 \mathrm{aA}$ & $6,7 \pm 2,4 \mathrm{aA}$ & $30,7 \pm 2,8 \mathrm{cA}$ & $1,2 \pm 0,3 \mathrm{aB}$ & $24,0 \pm 1,8 \mathrm{abA}$ & $4,0 \pm 1,0 \mathrm{aB}$ \\
\hline B. bassiana $6,0 \times 10^{12}$ & $8,0 \pm 0,5 a A$ & $3,5 \pm 0,4 \mathrm{aA}$ & $24,7 \pm 3,6$ bcA & $1,2 \pm 0,3 \mathrm{aB}$ & $22,0 \pm 2,5 a b A$ & $8,2 \pm 2,3 \mathrm{aB}$ \\
\hline lambda-cialotrina $7,5 \mathrm{~g}$ & $22,7 \pm 5,1 \mathrm{aA}$ & $9,5 \pm 1,3 \mathrm{aB}$ & $10,0 \pm 1,2 \mathrm{aA}$ & $0,5 \pm 0,1 \mathrm{aB}$ & $29,7 \pm 2,0$ abA & $2,5 \pm 0,8 \mathrm{aB}$ \\
\hline Testemunha & $11,0 \pm 1,0 \mathrm{aA}$ & $2,0 \pm 0,8 \mathrm{aA}$ & $21,7 \pm 2,3$ abcA & $0,7 \pm 0,3 \mathrm{aB}$ & $18,0 \pm 0,9 a A$ & $4,5 \pm 0,7 \mathrm{aB}$ \\
\hline F. & \multicolumn{2}{|c|}{0,62} & \multicolumn{2}{|c|}{2,25} & \multicolumn{2}{|c|}{1,53} \\
\hline CV (\%) 1 - produto & \multicolumn{2}{|c|}{37,89} & \multicolumn{2}{|c|}{6,30} & \multicolumn{2}{|c|}{26,12} \\
\hline CV (\%) 2 - cultivares & \multicolumn{2}{|c|}{39,62} & \multicolumn{2}{|c|}{25,13} & \multicolumn{2}{|c|}{28,93} \\
\hline \multirow{2}{*}{$\begin{array}{l}\text { Produtos } \\
\text { Dose i.a. ha-1 ou conídios ha-1 }\end{array}$} & \multicolumn{2}{|c|}{$30 \mathrm{DAE}$} & \multicolumn{2}{|c|}{$40 \mathrm{DAE}$} & \multicolumn{2}{|c|}{56 DAE } \\
\hline & DKB $175 \pm E P$ & $\begin{array}{l}\text { DKB } 390 \text { VT } \\
\text { PRO } \pm \text { EP }\end{array}$ & DKB $175 \pm E P$ & $\begin{array}{l}\text { DKB } 390 \mathrm{VT} \\
\text { PRO } \pm \text { EP }\end{array}$ & DKB $175 \pm E P$ & $\begin{array}{l}\text { DKB } 390 \text { VT } \\
\text { PRO } \pm \text { EP }\end{array}$ \\
\hline B. bassiana $2,0 \times 10^{12}$ & $54,7 \pm 2,4 \mathrm{aA}$ & $31,7 \pm 2,7 \mathrm{aA}$ & $22,5 \pm 0,3 a A$ & $0,2 \pm 0,4 a B$ & $2,7 \pm 0,4 a A$ & $0,2 \pm 0,1 \mathrm{aA}$ \\
\hline B. bassiana $4,0 \times 10^{12}$ & $49,2 \pm 2,5 \mathrm{aA}$ & $46,5 \pm 3,6 a A$ & $27,0 \pm 0,6 a A$ & $0,0 \pm 0,0 \mathrm{aB}$ & $8,5 \pm 3,0$ aA & $0,0 \pm 0,0 \mathrm{aA}$ \\
\hline B. bassiana $6,0 \times 10^{12}$ & $50,5 \pm 1,9 a A$ & $51,7 \pm 3,7 \mathrm{aA}$ & $20,2 \pm 0,5 a A$ & $0,0 \pm 0,0 \mathrm{aB}$ & $2,2 \pm 0,4 \mathrm{aA}$ & $3,0 \pm 1,5 \mathrm{aA}$ \\
\hline lambda-cialotrina $7,5 \mathrm{~g}$ & $53,0 \pm 1,9 \mathrm{aA}$ & $29,2 \pm 0,9 \mathrm{aA}$ & $30,0 \pm 0,8 \mathrm{aA}$ & $0,5 \pm 0,8 \mathrm{aB}$ & $4,7 \pm 0,3 a A$ & $0,2 \pm 0,1 \mathrm{aA}$ \\
\hline Testemunha & $58,7 \pm 3,6 a A$ & $40,0 \pm 2,1 \mathrm{aA}$ & $27,0 \pm 1,0 \mathrm{aA}$ & $0,5 \pm 0,4 \mathrm{aB}$ & $1,5 \pm 0,2 \mathrm{aA}$ & $0,0 \pm 0,0 \mathrm{aA}$ \\
\hline F. & \multicolumn{2}{|c|}{0,41} & \multicolumn{2}{|c|}{1,24} & \multicolumn{2}{|c|}{1,60} \\
\hline CV (\%) 1 - produto & \multicolumn{2}{|c|}{63,00} & \multicolumn{2}{|c|}{24,97} & \multicolumn{2}{|c|}{56,88} \\
\hline CV (\%) 2 - cultivares & \multicolumn{2}{|c|}{37,75} & \multicolumn{2}{|c|}{17,99} & \multicolumn{2}{|c|}{46,37} \\
\hline
\end{tabular}

DAE: Dias após a emergência; CV (\%): 34,41; F.: 1,28. Médias seguidas pela mesma letra minúscula, na coluna dentro de cada data amostrada, e maiúscula, na linha dentro de cada data amostrada, não diferem pelo teste Tukey a 5\% de probabilidade. Dados originais sem transformação. 
Os resultados referentes à eficiência do bioinseticida no controle de $S$. frugiperda em cultivar DKB 390 VT PRO (transgênico) foram desconsiderados, visto que a mortalidade das lagartas era causada pela própria tecnologia empregada no cultivar, resultado já esperado, pois, segundo CARNeIro et al. (2009), plantas com genes da bactéria Bacillus thuringiensis inseridas em sua constituição genotípica proporcionam uma alta mortalidade de lagartas.

Verifica-se que em plantas de milho convencional (DKB 175), independentemente ou náo dos defensivos aplicados, foram constatadas, no mínimo, plantas com sintomas de folhas raspadas (nota 2) com variação entre 30 e 43\%. Quanto à nota 3 (dano direto ao cartucho), na dose de 2,0 x $10^{12}$ conídios ha ${ }^{-1}$, ocorreu menor porcentagem de plantas danificadas (Fig. 1).

Com relação às plantas geneticamente modificadas $(\mathrm{DKB}$ 390 VT PRO), mesmo plantas sem aplicação (testemunha), ficou evidenciada a ausência de dano (nota 0 - plantas sem sintoma de ataque) em observação visual, ficando claro que as plantas de milho que contêm o gene $B t$ em sua constituição genética se mostram mais resistentes mediante o ataque de $S$. frugiperda (Fig. 1). Fato confirmado por Soberón et al. (2009), que disseram que a toxina $B t$ é expressa continuamente nos tecidos da planta, o que explica a eficácia de controle dessa tecnologia.
Resultados semelhantes foram evidenciados por ZANCANARO et al. (2012), que verificaram que o tratamento totalmente transgênico, como esperado, apresentou a menor intensidade de dano.

Foi observada uma reduzida população de $D$. luteipes em estágios iniciais da cultura do milho (Fig. 2), porém, quando observada a seletividade do bioinseticida a esse inimigo natural, constatou-se que a dose de 4,0 × $10^{12}$ conídios ha ${ }^{-1}$ foi mais seletiva, e a dose de $6,0 \times 10^{12}$ conídios ha ${ }^{-1}$, menos seletiva em cultivar de milho convencional. Para lavouras com milho transgênico DKB 390 VT PRO, verificou-se, de modo geral, maior seletividade da dose de 4,0 x $10^{12}$ conídios ha ${ }^{-1}$; porém, baixas populaçóes também foram evidenciadas na testemunha (sem aplicação) (Fig. 2). Cruz (1995) relatou que $D$. luteipes é o principal predador de lagartas na cultura do milho, principalmente de $S$. frugiperda, e FigueIREDo et al. (2006) ressaltaram que a intensidade dos danos de lagartas dessa espécie é elevada quando seus inimigos naturais não estão presentes na área de cultivo.

Em relação a $R$. maidis, verificou-se que em áreas tratadas com o bioinseticida a base de B. bassiana, não houve redução populacional. Diferentemente, em plantas submetidas a aplicação do inseticida químico padrão (lambda-cialotrina), evidenciou-se menor população da praga (Tabela 2).

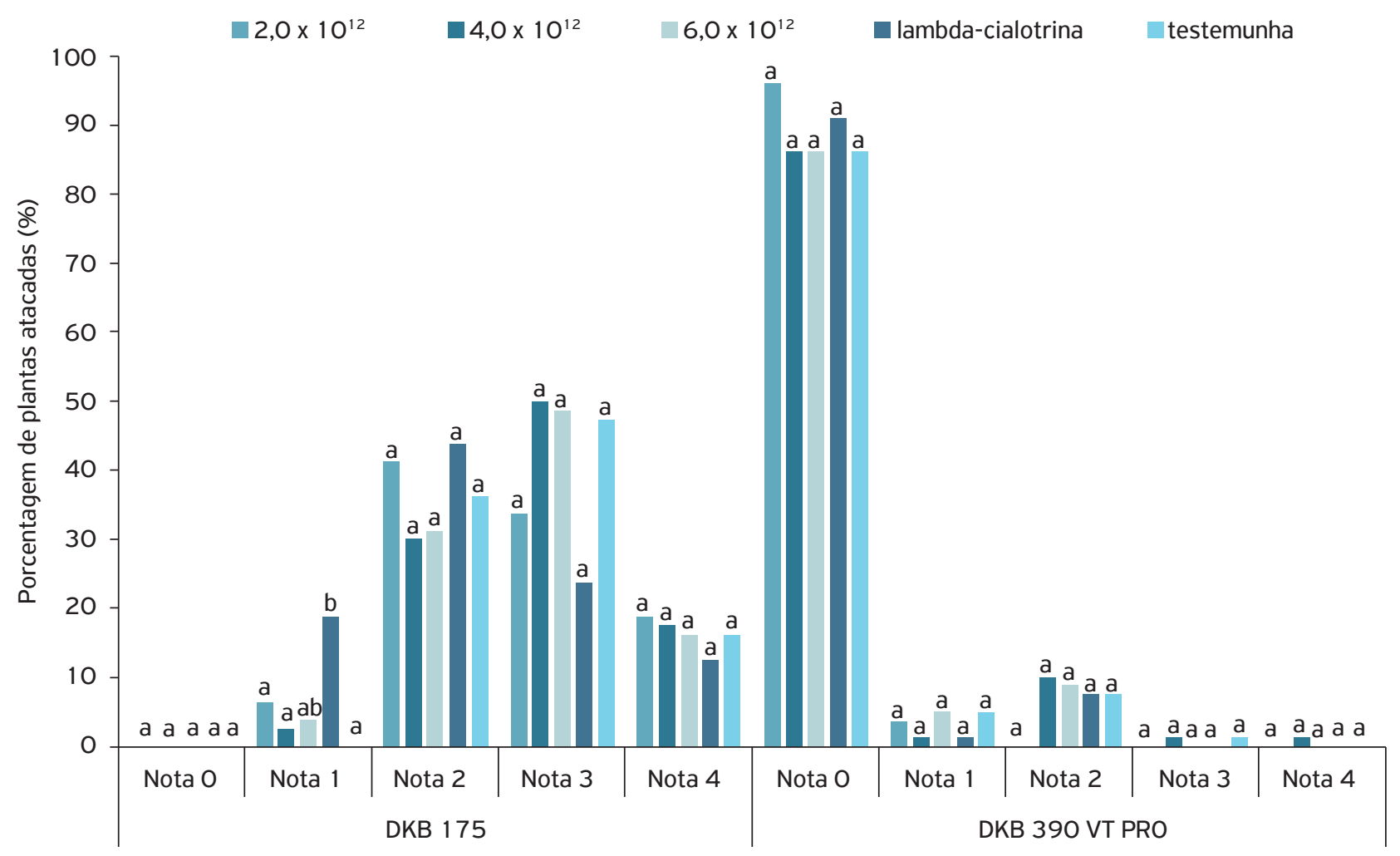

Nota O: plantas sem folhas danificadas; Nota 1: plantas com raspadura nas folhas; Nota 2: plantas apresentando furo nas folhas; Nota 3: plantas apresentando dano nas folhas e alguma lesão no cartucho; Nota 4: plantas apresentando cartucho destruído; Nota 5: plantas mortas.

Figura 1. Notas atribuídas aos danos causados por Spodptera frugiperda em plantas de milho transgênico e convencional submetidas a aplicações do fungo Beauveria bassiana em condições de campo. Agência Paulista de Tecnologia dos Agronegócios-Regional, São José do Rio Preto (SP), 2010-2011. 


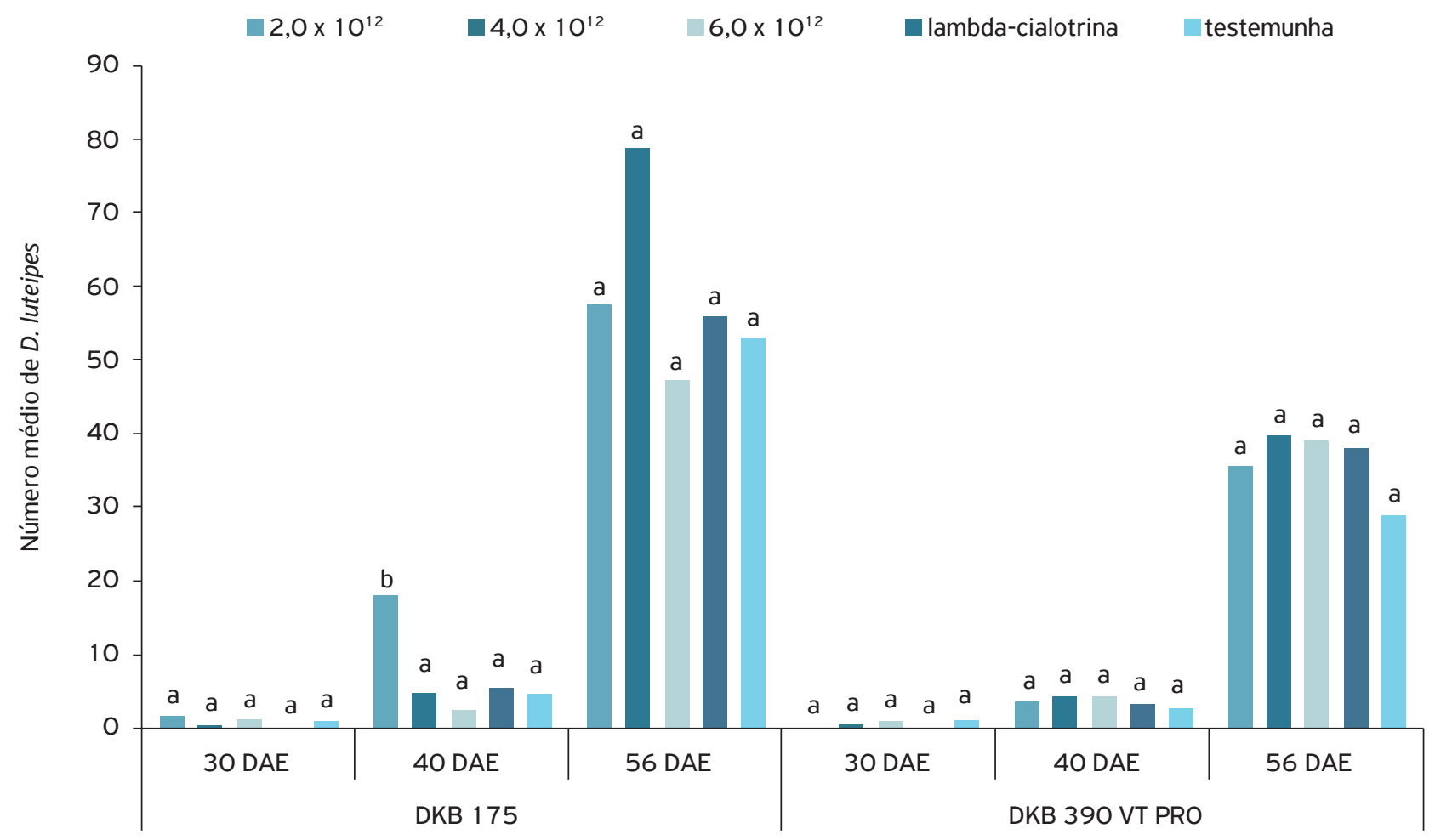

DAE: dias após a emergência. Médias seguidas pela mesma letra não diferem pelo teste Tukey a $5 \%$ de probabilidade.

Figura 2. Número médio de Doru luteipes em dez plantas de milho transgênico e convencional submetidas a aplicações de Beauveria bassiana em condições de campo com relação aos dias após a emergência. Agência Paulista de Tecnologia dos AgronegóciosRegional, São José de Rio Preto (SP), 2010-2011.

Tabela 2. Número (média + erro padrão) de pulgões Rhopalosiphum maidis em dez plantas de milho transgênico e convencional tratadas com o fungo Beauveria bassiana em condições de campo. Agência Paulista de Tecnologia dos Agronegócios-Regional, São José do Rio Preto (SP), 2010-2011.

\begin{tabular}{|c|c|c|c|c|c|c|}
\hline \multirow{2}{*}{$\begin{array}{l}\text { Produtos } \\
\text { Dose i.a. ha-1 ou conídios ha-1 }\end{array}$} & \multicolumn{2}{|c|}{$9 \mathrm{DAE}$} & \multicolumn{2}{|c|}{15 DAE } & \multicolumn{2}{|c|}{22 DAE } \\
\hline & DKB $175 \pm E P$ & $\begin{array}{c}\text { DKB } 390 \text { VT PRO } \\
\pm \text { EP }\end{array}$ & DKB $175 \pm E P$ & $\begin{array}{c}\text { DKB } 390 \text { VT PRO } \\
\pm \text { EP }\end{array}$ & DKB $175 \pm E P$ & $\begin{array}{l}\text { DKB } 390 \text { VT } \\
\text { PRO } \pm \text { EP }\end{array}$ \\
\hline B. bassiana $2,0 \times 10^{12}$ & $2,5 \pm 0,4 \mathrm{aA}$ & $1,0 \pm 0,2 \mathrm{aA}$ & $3,0 \pm 0,5 \mathrm{aA}$ & $4,7 \pm 0,8 \mathrm{aA}$ & $30,0 \pm 5,4 \mathrm{aA}$ & $27,0 \pm 5,1 \mathrm{aA}$ \\
\hline B. bassiana $4,0 \times 10^{12}$ & $0,5 \pm 0,1 \mathrm{aA}$ & $2,5 \pm 0,3$ aA & $5,2 \pm 0,6 \mathrm{aA}$ & $5,7 \pm 1,0 \mathrm{aA}$ & $10,5 \pm 2,4 \mathrm{aA}$ & $25,5 \pm 5,6 a A$ \\
\hline B. bassiana $6,0 \times 10^{12}$ & $1,5 \pm 0,4 \mathrm{aA}$ & $1,0 \pm 0,2 \mathrm{aA}$ & $2,5 \pm 0,3 \mathrm{aA}$ & $11,0 \pm 1,5 \mathrm{aB}$ & $24,0 \pm 5,9 \mathrm{aA}$ & $29,0 \pm 6,2 \mathrm{aA}$ \\
\hline lambda-cialotrina $7,5 \mathrm{~g}$ & $2,5 \pm 0,4 \mathrm{aA}$ & $1,5 \pm 0,5 \mathrm{aA}$ & $7,2 \pm 1,0 \mathrm{aA}$ & $9,5 \pm 1,3 \mathrm{aA}$ & $27,5 \pm 3,8 \mathrm{aA}$ & $17,7 \pm 3,2 \mathrm{aA}$ \\
\hline Testemunha & $1,0 \pm 0,2 \mathrm{aA}$ & $0,3 \pm 0,1 \mathrm{aA}$ & $3,5 \pm 0,5 \mathrm{aA}$ & $10,2 \pm 1,5 \mathrm{aB}$ & $19,7 \pm 3,1 \mathrm{aA}$ & $51,0 \pm 5,5 a B$ \\
\hline F. & \multicolumn{2}{|c|}{2,25} & \multicolumn{2}{|c|}{2,53} & \multicolumn{2}{|c|}{1,49} \\
\hline CV (\%) 1 - produtos & \multicolumn{2}{|c|}{42,31} & \multicolumn{2}{|c|}{18,94} & \multicolumn{2}{|c|}{27,12} \\
\hline CV (\%) 2 - cultivares & \multicolumn{2}{|c|}{26,82} & \multicolumn{2}{|c|}{22,34} & \multicolumn{2}{|c|}{36,84} \\
\hline & \multicolumn{2}{|c|}{30 DAE } & \multicolumn{2}{|c|}{40 DAE } & \multicolumn{2}{|c|}{56 DAE } \\
\hline Dose i.a. ha-1 ou conídios ha-1 & DKB $175 \pm E P$ & $\begin{array}{c}\text { DKB } 390 \text { VT PRO } \\
\pm \text { EP }\end{array}$ & DKB $175 \pm E P$ & $\begin{array}{c}\text { DKB } 390 \text { VT PRO } \\
\pm \text { EP }\end{array}$ & DKB $175 \pm E P$ & $\begin{array}{l}\text { DKB } 390 \text { VT } \\
\text { PRO } \pm E P\end{array}$ \\
\hline B. bassiana $2,0 \times 10^{12}$ & $590,00 \pm 118,6 b A$ & $482,5 \pm 33,9$ a A & $1244,2 \pm 132,4$ a $A$ & $1616,0 \pm 379,6$ a $A$ & $23,2 \pm 7,0 \mathrm{ab} A$ & $1,5 \pm 0,7$ a $A$ \\
\hline B. bassiana $4,0 \times 10^{12}$ & $298,2 \pm 37,6 \mathrm{abA}$ & $202,5 \pm 40,2$ a A & $1002,0 \pm 173,4 \mathrm{a} A$ & $2111,7 \pm 335,7$ a A & $3,0 \pm 0,6$ a $A$ & $6,5 \pm 1,6$ a $A$ \\
\hline B. bassiana $6,0 \times 10^{12}$ & $376,2 \pm 22,3 \mathrm{abA}$ & $314,7 \pm 8,5$ a $A$ & $505,0 \pm 59,9$ a A & $1852,5 \pm 161,7$ a B & $12,0 \pm 3,6 a b A$ & $0,7 \pm 0,3$ a $A$ \\
\hline lambda-cialotrina $7,5 \mathrm{~g}$ & $146,2 \pm 29,6 \mathrm{aA}$ & $154,5 \pm 17,7$ a $A$ & $454,5 \pm 24,4$ a A & $3108,7 \pm 362,8$ a B & $49,0 \pm 12,3 \mathrm{~b} \mathrm{~A}$ & $0,5 \pm 0,1 \mathrm{a} B$ \\
\hline Testemunha & $289,2 \pm 54,8 \mathrm{abA}$ & $343,5 \pm 34,8$ a A & $640,7 \pm 88,9$ a A & $1523,7 \pm 166,4$ a $A$ & $5,5 \pm 1,5$ a $A$ & $3,0 \pm 0,7$ a $A$ \\
\hline F. & \multicolumn{2}{|c|}{0,56} & \multicolumn{2}{|c|}{1,83} & \multicolumn{2}{|c|}{2,78} \\
\hline CV (\%) 1 - produtos & \multicolumn{2}{|c|}{45,06} & \multicolumn{2}{|c|}{23,49} & \multicolumn{2}{|c|}{84,49} \\
\hline CV (\%) 2 - cultivares & \multicolumn{2}{|c|}{23,75} & \multicolumn{2}{|c|}{33,42} & \multicolumn{2}{|c|}{69,01} \\
\hline
\end{tabular}

DAE: dias após a emergência; CV (\%): 37,10; F.: 1,90. Médias seguidas pela mesma letra minúscula, na coluna dentro de cada data amostrada, e maiúscula, na linha, não diferem pelo teste Tukey a $5 \%$ de probabilidade. Dados originais sem transformação. 
A redução populacional do pulgão-do-milho foi observada somente a partir de $40 \mathrm{DAE}$ em ambos os cultivares, sendo a redução mais pronunciada em plantas transgênicas tratadas com fungo B. bassiana em dose de 4,0 x $10^{12}$ conídios ha $^{-1}$, supondo que tal redução tenha ocorrido pela maior ação de inimigos naturais nesse período ou até mesmo pelo fato de a cultura estar próxima do pendoamento (uma condição desfavorável ao pulgão). Segundo Maia et al. (2005), a flutuação populacional de $R$. maidis é influenciada pela densidade de inimigos naturais, como larvas de Chrysoperla externa (8 larvas/planta). Vale ainda ressaltar que aos $56 \mathrm{DAE}$ verificou-se elevada população de pulgóes em lavouras tratadas com inseticida padrão (49 pulgóes) (Tabela 2). Embora não se tenha muitos trabalhos publicados detalhando a açấo da tecnologia do milho $B t$ sobre afídeos, os resultados da presente pesquisa possibilitam observar maiores populaçóes de $R$. maidis em cultivar geneticamente modificado (DKB 390 VT PRO), sendo tal superioridade confirmada aos $40 \mathrm{DAE}$, em que todos os tratamentos apresentaram médias superiores às do cultivar convencional (DKB 175) (Tabela 2).

Porém, Melatti et al. (2010), estudando a ação de 400 estirpes de B. thuringiensis pertencentes ao Banco de Germoplasma de Bacillus spp. da Empresa Brasileira de Pesquisa Agropecuária (Embrapa) sobre o pulgão Aphis gossypii (Glover, 1877) (Hemiptera: Aphididae), observaram que as estirpes S29, S40, S616, S1168 e S1576 têm açấo tóxica contra o pulgão do algodoeiro, quando utilizado de forma sistêmica na planta de algodáo, podendo, assim, essas plantas transgênicas terem influenciado ou não na populaçáo de $R$. maidis estudada no presente trabalho.

Quanto à eficiência bioinseticida no controle do pulgão-do-milho, observou-se $75 \%$ de eficiência em tratamento de $6,0 \times 10^{12}$ conídios ha ${ }^{-1}$ aos 56 DAE em lavouras de milho geneticamente modificado, porém em cultivar convencional a dose mais eficiente foi de 4,0 x $10^{12}$ conídios ha ${ }^{-1}$ aos 22 DAE (39\%).

\section{CONCLUSÕES}

Nas condiçôes em que os testes foram realizados, a associação de $B$. bassiana à tecnologia $B t$ náo produziu resultados satisfatórios no controle de $S$. frugiperda e $R$. maidis.

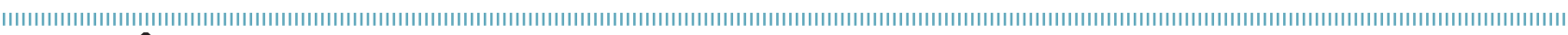
REFERÊNCIAS

ABBOTT, W.S. A method of computing the effectiveness of an insecticide. Journal of Economic Entomology, v.18, n.1, p.265-266, 1925.

AFONSO JUNIOR, V.A. Eficiência dos fungos Metarhizium anisopliae e Beauveria bassiana no controle de Spodoptera frugiperda em milho "safrinha". In: SIMPÓSIO DE CONTROLE BIOLÓGICO, 12. Resumos, Bento Gonçalves, 2009. Bento Gonçalves: 2009.

AGROFIT - Sistema de Agrotóxicos Fitossanitários. Disponível em: <http://agrofit.agricultura.gov.br/agrofit_cons/principal_ agrofit_cons>. Acesso em: 01 nov. 2013.

ALVES, S.B. Controle Microbiano de Insetos. Piracicaba: FEALQ, 1998. 1163 p.

BORÉM, A.; SANTOS, F.R. Biotecnologia simplificada. Viçosa: LEITURA, 2002. p.249.

CANINI, F.L.S.; DANIELI, T.; VERCESI, D.B.; GOMES, A.A.L.; RAIZARO, V.C.; PINTO, A.D.E.S. Eficiência do fungo Metarhizium anisopliae no controle de Spodoptera frugiperda aplicado em diferentes estádios fenológicos da cultura do milho em Ribeirão Preto, SP. In: SIMPÓSIO DE CONTROLE BIOLÓGICO, 12., 2009, Bento Gonçalves, RS. Resumos. Bento Gonçalves: 2009. p.88.

CANINI, F.L.S.; DANIELI, T.; VERCESI, D.B; GOMES, A.A.L.; RAIZARO, V.C.; PINTO, A.D.E.S. (2008) Eficiência dos fungos Metarhizium anisopliae e Beauveria bassiana no controle da lagarta-docartucho, Spodoptera frugiperda, em milho de segunda safra.
In: CONGRESSO BRASILEIRO DE ENTOMOLOGIA, 12., 2008, Uberlândia, MG. Resumos, Uberlândia: 2008. p.1581.

CARNEIRO, A.A.; VALICENTE, F.H.; WAQUIL, J.M.; VASCONCELOS, M.J.V.; CARNEIRO, N.P.; MENDES, S.M. Milho Bt: Teoria e Prática da Produção de Plantas Transgênicas Resistentes a Insetos-Praga. Sete Lagoas: EMBRAPA, 2009. 26p. (Circular Técnica 135).

CARVALHO, R.P.L. Danos, flutuação da população, controle e comportamento de Spodoptera frugiperda (SMITH, 1797) e sustentabilidade de diferentes genótipos de milho em condições de campo. 1970. 170f. Tese (Doutorado em Agronomia) Escola Superior de Agricultura “Luis de Queiroz”, Piracicaba, 1970.

CRUZ, I. Lagarta-do-cartucho na cultura do milho. Sete Lagoas: EMBRAPA, 1995. 45p. (Circular Técnica 21).

CRUZ, I.; FIGUEREIDO, M.L.C.; MATOSO, M.J.M. Controle biológico de Spodopterafrugiperda utilizando o parasitóide de ovos Trichogramma. Sete Lagoas: EMBRAPA, 1999. 40p. (Circular Técnica 30).

DOURADO, P.M. Resistencia de Spodoptera frugiperda (Lepdoptera: Nocutidae) a spinosad no Brasil. 2009. 71 f. Dissertação (Mestrado em Agronomia) Escola Superior de Agricultura "Luis de Queiroz", Piracicaba, 2009.

FIGUEIREDO, M.D.E.L.C.; MARTINS-DIAS, A.M.P.; CRUZ, I. Relação entre a lagarta-do-cartucho e seus agentes de controle biológico natural na produção de milho. Pesquisa Agropecuária Brasileira, v.41, n.1, p.1693-1698, 2006. 
FONSECA, A.R.; CRUZ, I.; CARVALHO, C.F.; SOUZA, B. Resistência de genótipos de sorgo ao pulgão Rhopalosiphum maidis (Fitch, 1856) (Hemiptera: Aphididae) e efeito no desenvolvimento da planta. Ciência e Agrotecnologia, v.28, n.3, p.585-592, 2004.

GUTIERREZ, L.S.; CARDENAS, W.H.K.; GUTIERREZ, G.S. Estudio bioeconómico de la utilización de Metarhizium anisopliae junto con inhibidores de síntesis de quitina en el control del gusano cogollero en sorgo. Manejo Integrado de Plagas, v.36, n. 1, p.1-6, 1995.

MAIA, W.J.M.S.; CRUZ, I.; CARVALHO, C.F.; SOUZA, B.; WAQUIL, J.M.; PINHO, R.G.V.; CARVALHO, S.P.; MAIA, T.J.A.F.; LOUREIRO, I. Efeito do estádio fenológico do milho (Zea mays $L$.) sobre a infestação pelo pulgão Rhopalosiphum maidis (FITCH, 1856). Revista Brasileira de Milho e Sorgo, v.4, n.3, p.308-315, 2005.

MARTINS, G.M.; TOSCANO, L.C.; TOMQUELSKI, G.V.; MARUYAMA, W.I. Inseticidas químicos e microbianos no controle da lagartado-cartucho na fase inicial da cultura do milho. Caatinga, v.22, n.2, p.170-174, 2009

MONNERAT, R.G.; MELATTI, V.M.; PRAÇA, L.; MARTINS, E.; SUJII, E.; BERRY, C.; Selection of Bacillus thuringiensis Strains Toxic Against Cotton Aphid, Aphis gossypii (Glover, 1877) (Hemiptera: Aphididae). BioAssay, v.5, n.1, p.1- 4, 2010.

REDOAN, A.C.M. Seletividade de inseticidas para Doru luteipes (Scudder, 1876) (Dermaptera: Forficulidae) com registro para o controle da Spodoptera frugiperda (Smith) (Lepidoptera: Noctuidae) em milho. 201 1. 104f. Dissertação (Mestrado em Entomologia). Universidade Federal de Lavras, Lavras, 2011.

SOBERÓN, M.; GILL, S.S.; BRAVO, A. Signaling versus punching hole: how do Bacillus thuringiensis toxins kill insect midgut cells. Cellular and Molecular Life Sciences, v.66, n. 1, p.1337-1349, 2009.

THOMAZONI, D.; FORMENTINI, M.A.; MAMPRIM, A.P.; MARTINELO, L.; RODRIGUES, L.D.I.F.; FANTI, A.L.P.; ALVES, L.F.A. Seleção de Isolados de Beauveria bassiana e Metarhizium anisopliae visando o Controle da lagarta-do-cartucho Spodoptera frugiperda (J.E. Smith, 1797) (Lepidoptera: Noctuidae). Revista Brasileira de Agroecologia, v.4, n.2, p.2776-2779, 2009.

VALICENTE, F.H.; TUELHER, E.S. Controle Biológico da Lagarta do Cartucho, Spodoptera frugiperda, com Baculovírus. Sete Lagoas: EMBRAPA, 2009. 15p. (Circular Técnica 114).

VIANA, P.A.; PRATES, H.T.; RIBEIRO, P.E.A. Uso do Extrato Aquoso de Folhas de NIM para o Controle de Spodoptera frugiperda na Cultura do Milho. Sete Lagoas: EMBRAPA, 2006. 5p. (Circular Técnica 88).

WIDSTRON, N.W. An evaluation of methods for measuring corn ear worm injury. Journal of Economic Entomology, v.60, n.1, p.791-794, 1967.

ZANCANARO, P.O.; BUCHWEITZ, E.D.; BOICA JUNIOR, A.L.; MORO, J.R. Avaliação de tecnologias de refúgio no cultivo de milho transgênico. Pesquisa Agropecuária Brasileira, v.47, n.7, p.886-891, 2012. 